\title{
Longitudinal DNA Methylation Profiling of the Rectal Mucosa Identifies Cell-specific Signatures of Disease Status, Severity and Clinical Outcomes in Ulcerative Colitis
}

\section{Cell-specific DNA methylation signatures of UC}

Suresh Venkateswaran ${ }^{1}$, Hari K Somineni ${ }^{1}$, Jason D. Matthews ${ }^{1,}$ Varun Kilaru $^{2}$, Jeffrey S Hyams ${ }^{3}$, Lee A Denson ${ }^{4}$, Richard Kellamayer ${ }^{5}$, Greg Gibson ${ }^{6}$, David J Cutler $^{7}$, Karen N Conneely ${ }^{7,8, \$}$, Alicia K Smith ${ }^{2,8,9, \$}$ and Subra Kugathasan ${ }^{1,7,8, \$, *}$

\section{Author Affiliations}

1 Division of Pediatric Gastroenterology, Department of Pediatrics, Emory University School of Medicine \& Children's Healthcare of Atlanta, Atlanta, GA, USA

2 Department of Gynecology \& Obstetrics, Emory University School of Medicine, Atlanta, GA, USA

3 Division of Digestive Diseases, Hepatology, and Nutrition, Connecticut Children's Medical Center, Hartford, CT, USA

4 Division of Pediatric Gastroenterology, Hepatology, and Nutrition, Cincinnati Children's Hospital Medical Center, Cincinnati, OH, USA

5 Section of Pediatric Gastroenterology, Texas Children's Hospital Baylor College of Medicine, Houston, TX, USA

6 Center for Integrative Genomics, Georgia Institute of Technology, Atlanta, GA, USA

7 Department of Human Genetics, Emory University, Atlanta, GA, USA

8 Genetics and Molecular Biology Program, Emory University, Atlanta, GA, USA

9 Department of Psychiatry \& Behavioral Sciences, Emory University, Atlanta, GA, USA

\$ Equal contribution for last authorship

*Corresponding author: $\quad$ Subra Kugathasan, MD

Division of Pediatric Gastroenterology

Emory University School of Medicine \&

Children's Healthcare of Atlanta

1760 Haygood Drive, W-427

Atlanta, GA 30322

Tel: 4047271316

Fax: 4047274069

e-mail: skugath@emory.edu 
medRxiv preprint doi: https://doi.org/10.1101/2022.01.28.22269598; this version posted January 30, 2022. The copyright holder for this preprint

(which was not certified by peer review) is the author/funder, who has granted medRxiv a license to display the preprint in perpetuity.

It is made available under a CC-BY-NC 4.0 International license .

\begin{abstract}
In peripheral blood, DNA methylation (DNAm) patterns in inflammatory bowel disease patients reflect inflammatory status rather than disease status. Here, we studied DNAm in diseased rectal mucosa from ulcerative colitis (UC) patients, conducting a cell-type-specific EWAS in epithelial, immune and fibroblast cells to understand DNAm changes across disease states, course, and clinical outcomes. At diagnosis, rectal mucosa in UC exhibited a lower proportion of epithelial cells and fibroblasts, and higher proportion of immune cells, along with 3504, 910, and 2279 altered DNAm sites as detected in our cellspecific EWAS, respectively. While treatment had significant effects on DNAm of immune cells, its effects on fibroblasts and epithelial cells were attenuated. Those requiring colectomy exhibited cell composition and DNAm patterns at follow-up more like disease onset than patients who did not require colectomy. Collectively DNAm and gene expression analysis suggest that targeting epithelial genes involved in barrier function may improve clinical outcomes.
\end{abstract}


medRxiv preprint doi: https://doi.org/10.1101/2022.01.28.22269598; this version posted January 30, 2022. The copyright holder for this preprint (which was not certified by peer review) is the author/funder, who has granted medRxiv a license to display the preprint in perpetuity.

It is made available under a CC-BY-NC 4.0 International license .

\section{Background}

Ulcerative colitis (UC) is a form of inflammatory bowel disease that affects an estimated $1 \%$ of the population in North America and Europe ${ }^{1}$. The chronic inflammation is limited to colon in UC, and is usually remitting and relapsing in nature, but repeated inflammation of the colon invariably results in progressive tissue damage. By nature, UC subjects exhibit evidence of systemic inflammation during the active disease, and $\sim 10 \%$ of all UC subjects also have involvement of extra-intestinal manifestations ${ }^{2}$. Although UC is heterogeneous in disease course and outcome, the need for colectomy shortly after diagnosis is the least favorable outcome. Genome-wide association studies have proven the role of immune-associated genetic variants beyond doubt in $\mathrm{UC}^{3-5}$, but in total these variants have accounted for less than $10 \%$ of the disease susceptibility, and an even smaller proportion of disease outcome. So far, these genetic studies have pointed to few influences of disease beyond the genetic regulation of the immune system itself. Although several drugs are already available to target the immune system in UC, and more immune targeting therapies are being developed, nearly half of UC patients show insufficient response to these therapies. Thus, we asked if it is possible to identify therapeutic targets for UC other than the immune system itself.

Since genetics itself has pointed largely at the immune system, we turned to other molecular systems implicated in UC pathogenesis ${ }^{6}$. DNA methylation (DNAm) signatures ${ }^{7-9}$ have been associated with UC phenotypes. However, to date the majority of DNAm studies in IBD have focused on study of peripheral blood ${ }^{10-15}$. We have shown that DNAm changes in peripheral blood cells associate primarily with inflammatory status rather than disease status ${ }^{16}$, and that methylation patterns in blood largely return to "normal" after anti-inflammatory treatment, regardless of the underlying disease state. To find cells whose molecular signatures might better reflect the disease state, we move to the location of disease itself. Here we examine genome-wide DNAm of the rectal tissue in an inception cohort of UC at 2 time points, once at diagnosis (treatment naïve) and subsequently at follow-up, to explore how longitudinal DNAm associates with disease onset, disease progression and outcome. Similar studies have been done only in small sets of patients, and in select cellular compartments such as purified epithelial cells ${ }^{17,18}$. 
Site-specific DNAm differences have been reported in IBD from peripheral blood ${ }^{16}$, and intestinal biopsies $^{17-19}$, but the analysis on the source of the cell type which driving those signals, the temporal relationship between DNAm, disease, and the most unfavorable clinical outcomes (e.g., colectomy status) were not studied for therapeutic benefits. Thus, in this study we conducted a cell type-specific, epigenome-wide association study (EWAS) of DNA methylation ( 850,000 sites) changes in the rectal mucosa at diagnosis, follow-up, and across disease phenotypes and clinical outcome trajectories (colectomy and mucosal healing) using rectal mucosal biopsies collected for the PROTECT pediatric UC

inception cohort ${ }^{20-22}$. Our analysis examined interactions between DNAm-based estimates of proportions of three major cell components of intestinal tissues - epithelial, immune cells and fibroblasts (as a measure of mesenchyme) - and DNAm to identify cell-specific differential DNAm patterns and associated gene expression from the same patients to evaluate disease status, disease course, disease severity, and colectomy status as clinical outcomes ${ }^{23}$ with the goal of finding patterns consistent with the cause of disease severity (rather than consequence) to serve as potential targets for molecular therapies.

\section{Results}

Altered DNAm in the epithelial, immune and fibroblast compartments are associated with UC at diagnosis. We used rectal mucosal biopsies to profile DNAm changes associated with UC. Principal component (PC) analysis of DNAm levels at $\sim 820 \mathrm{~K} \mathrm{CpG}$ sites in the mucosa showed separate clusters for UC at diagnosis $(n=211)$ and controls $(n=85)$ (Supplementary Fig. 1). We observed that PC1 and PC2 explained $20.1 \%$ and $8 \%$ of the variance in DNAm, respectively. Thus, we performed a traditional EWAS and identified 99,989 DNAm sites associated with UC at diagnosis (FDR $<0.05$; Supplementary Fig. 2). Identification of this large number of sites may reflect inflammation or unmeasured cellular heterogeneity, but is consistent with the high proportion of variation explained in our PC analysis, and suggests the possibility of a strong but complex DNAm signature of UC. To better understand what drives these large-scale differences in DNAm, we next decomposed our bulk signatures into constituent cell-type proportions (epithelial, immune, and fibroblast cells) via the EpiDISH ${ }^{24}$ algorithms. 
medRxiv preprint doi: https://doi.org/10.1101/2022.01.28.22269598; this version posted January 30, 2022. The copyright holder for this preprint (which was not certified by peer review) is the author/funder, who has granted medRxiv a license to display the preprint in perpetuity.

It is made available under a CC-BY-NC 4.0 International license .

Fig. 1a shows estimated cellular proportions based on DNAm signatures in UC at diagnosis vs. control samples for three primary cell types (epithelial, immune, and fibroblast cells). The estimated cell proportions from mucosal DNAm profiles shows a decrease in the proportion of epithelial cells $(P<2.2 \mathrm{e}-$ 16) as well as fibroblasts $(P=5 \mathrm{e}-07)$ and increasing proportions of immune cells $(P<2.2 \mathrm{e}-16)$, changes that are consistent with damaged and inflamed mucosa ${ }^{25-27}$. Cell-specific EWAS between UC at diagnosis $(\mathrm{n}=211)$ and controls $(\mathrm{n}=85)$ revealed 3,504 (Fig. 1b top panel; Supplementary Table 1A), 2,279 (Fig. 1b middle panel and Supplementary Table 2a) and 910 (Fig. 1c bottom panel and Supplementary Table 3a) differentially methylated $\mathrm{CpG}$ sites in epithelial, immune and fibroblast cells, respectively at FDR $<0.05$. Overall, these data suggest the possibility that cell-type-specific changes in DNAm in the rectal mucosa can be leveraged to differentiate diseased tissue from healthy individuals as well as and behavior during disease.

Regulatory potential of the differentially methylated CpG sites in UC. To gain insight into the regulatory potential of our differentially methylated $\mathrm{CpG}$ sites, we identified the nearest genes annotated to these $\mathrm{CpGs}$ in the Illumina manifest file. Differentially methylated $\mathrm{CpG}$ sites in epithelial ( $\mathrm{n}=3504$ CpGs), immune (n=2279 CpGs) and fibroblast (n=910 CpGs) cells were annotated to 1932, 1338 and 561 protein-coding genes, respectively. We first examined the association between the differentially methylated $\mathrm{CpG}$ sites and the gene expression levels of their corresponding genes in the rectal mucosa (CpG-gene pairs) in a subset of individuals $(\mathrm{n}=119)$ with both DNAm and gene expression data, and identified 526 genes associated with $700 \mathrm{CpG}$ sites in epithelial cells (Supplementary Table 1b), 173 genes associated with 210 CpG sites in immune cells (Supplementary Table 2b) and 63 genes associated with 145 CpG sites in fibroblasts (Supplementary Table 3b) at FDR $<0.05$. For these sets of genes, we next performed differential expression analysis comparing expression in rectal mucosa biopsies taken from patients with UC at diagnosis $(n=206)$ vs. biopsies taken from non-IBD individuals $(n=20) .488$ (93\%) of the 526 epithelial-specific differentially methylated CpG-associated genes were associated with UC at diagnosis (FDR < 0.05; (Supplementary Table 1c). Similarly, 150 (86\%) of the 173 immune- 
medRxiv preprint doi: https://doi.org/10.1101/2022.01.28.22269598; this version posted January 30, 2022. The copyright holder for this preprint (which was not certified by peer review) is the author/funder, who has granted medRxiv a license to display the preprint in perpetuity.

It is made available under a CC-BY-NC 4.0 International license .

specific CpG-associated genes (Supplementary Table 2c) and 56 (87\%) of the 63 fibroblast-specific CpG-associated genes (Supplementary Table 3c) were differentially expressed between patients with $\mathrm{UC}$ at diagnosis and non-IBD controls (FDR < 0.05; Fig. 1c). The observation that the majority of the genes found to be associated with UC-specific CpG sites also demonstrated changes in steady state levels of mRNA detectable in the mucosa highlights the regulatory potential of our differentially methylated CpG sites.

Biological relevance of the differentially methylated CpG sites in UC. GO analysis revealed that the set of genes $(n=488)$ associated with the differentially methylated $\mathrm{CpG}$ sites in epithelial cells was enriched for numerous biological processes related to epithelial function, including changes in wound response, GTPase signaling and cell migration (Fig. 1d top panel; Supplementary Tables 1D and 1E). Similarly, genes associated with immune cell-specific CpGs $(n=150)$ showed an enrichment for immune function related processes, including cell activation and signaling (Fig. 1d bottom panel; Supplementary Tables 2D and 2E), all of which are expected to occur in the damaged mucosa ${ }^{28-31}$. On the other hand, we did not detect any pathway level enrichment for genes associated with fibroblastspecific $\mathrm{CpG}$ sites $(\mathrm{n}=56)$ at FDR $<0.05$.

Taken together, these data suggest that DNAm patterns in different cell populations may be reflecting different aspects of the disease. Immune cell-specific responses are consistent with effects of ongoing inflammation. Immune cell DNAm in rectal tissue, as well as in blood, may be more the consequence of disease caused inflammation than it is the underlying cause of UC or disease progression. The epithelial compartment, on the other hand, with observable differences in wound response and cell migration pathways (prior to treatment) might provide insight into why some individuals fail to respond to effective anti-inflammatory treatments.

DNAm changes in the rectal mucosa of patients with UC post-treatment. To assess the cellular and molecular changes in the rectal mucosa of patients with UC after treatment, we next examined cellular 
medRxiv preprint doi: https://doi.org/10.1101/2022.01.28.22269598; this version posted January 30, 2022. The copyright holder for this preprint (which was not certified by peer review) is the author/funder, who has granted medRxiv a license to display the preprint in perpetuity.

It is made available under a CC-BY-NC 4.0 International license .

proportions and DNAm profiles at follow-up (n=73; Fig. 2). Clinical activity and/or disease severity in pediatric patients with UC is monitored by a validated activity index known as pediatric UC activity index $(\mathrm{PUCAI})^{32}$. The PUCAI scores of patients at follow-up were significantly lower than those obtained at the time of diagnosis (Supplementary Fig. 4a) consistent with patient's disease activity improving, on average, after treatment. Consistent with this, we observed a corresponding change in the estimated proportions of epithelial, immune and fibroblast compartments (Fig. 2a). Compared to UC at diagnosis, we observe an expansion in the proportion of epithelial and fibroblast compartments at follow-up, and depletion of immune cells, indicating that inflammation has, on average, decreased, and that some mucosal healing was underway.

Our cell type-specific EWAS comparing DNAm levels at the time of follow-up to those obtained at the time of diagnosis within the same 73 individuals found $668 \mathrm{CpG}$ sites differentially methylated within the immune compartment (FDR $<0.05$; Fig. 2b middle panel; Supplementary Fig. 4c, Supplementary Table 4a). For the majority of significant sites, the direction of the changes moved DNAm levels in cases after treatment closer to levels seen in controls. These patterns are consistent with DNAm levels in the immune compartment reflecting systemic immune status, and thus responding to systemic anti-inflammatory therapies. On the other hand, EWAS comparing DNAm levels at the time of follow-up to those obtained at the time of diagnosis did not reveal any differentially methylated CpG sites in the epithelial (Fig. 2b, top panel, Supplementary Fig. 4b) and fibroblast compartments (Fig. 2b, last panel, Supplementary Fig. 4d). This is consistent with epithelial and fibroblast cell populations being less reactive to treatment than the immune compartment.

To identify the impact of treatment effects on DNAm sites, we compared the DNAm differences observed for UC at diagnosis vs. controls, and UC at disease course vs. UC at diagnosis. The EWAS in Fig. 1b shows the CpG sites that are differentially methylated between newly diagnosed UC patients and controls, while the EWAS in Fig. 2d shows the CpG sites that are differentially methylated in UC patients before and after treatment. Fig. 2c shows that for CpGs significant in each of the three compartments in the UC 
medRxiv preprint doi: https://doi.org/10.1101/2022.01.28.22269598; this version posted January 30, 2022. The copyright holder for this preprint (which was not certified by peer review) is the author/funder, who has granted medRxiv a license to display the preprint in perpetuity.

It is made available under a CC-BY-NC 4.0 International license.

vs. control EWAS (Fig. 1b), there is a negative correlation in effect sizes from the two EWAS; this is consistent with a pattern where CpGs showing DNAm differences in patients at the time of diagnosis return to control levels upon treatment. Stronger negative correlations were observed for sites associated with UC in epithelial cells $(\mathrm{R}=-0.68)$ or fibroblasts $(\mathrm{R}=-0.47)$ vs. those associated in immune cells $(\mathrm{R}=-$ 0.33); however, significant pre- vs. post-treatment DNAm differences were only observed in immune cells (Fig. 2b, middle panel), with $96 \mathrm{CpG}$ sites showing significant DNAm differences in immune cells in both the case-control and pre-post analyses. For these 96 sites we observed a strong negative correlation $(\mathrm{R}=-0.86)$, with DNAm levels of 95 of these sites moving in the opposite direction from onset and trending towards controls and only one site (cg17642041, located in the transcription start site of the $C C R 9$ gene) trending away from control levels (maroon dot in Fig. $2 \mathrm{C}$ immune cell panels). We observed the same general pattern $(\mathrm{R}=-0.34)$ at all the $668 \mathrm{CpG}$ sites that differed between diagnosis and follow-up UC: 154 of $668 \mathrm{CpG}$ sites were significantly different at follow-up (FDR < 0.05) with a very strong negative correlation $(\mathrm{R}=-0.80)$ between onset and follow-up (Fig. 2d; Supplementary Table 4e).

Extending this analysis to all $\sim 820 \mathrm{~K} \mathrm{CpG} \mathrm{sites} \mathrm{analyzed} \mathrm{across} \mathrm{epigenome-wide,} \mathrm{we} \mathrm{still} \mathrm{observed}$ significant negative correlations between effect sizes $(R=-0.21$ for epithelial cells; $R=-0.16$ for immune cells; $\mathrm{R}=-0.21$ for fibroblasts; Supplementary Fig. 5), suggesting that at a broad scale, the epigenomic level the DNAm profiles observed at follow-up were trending towards those observed in controls. Of the 2279 sites differing between UC at diagnosis and controls in immune cells (from Fig. 1b, middle panel), 33 showed a significant negative association (epigenome-wide) in the comparison of cases vs. controls and a significant positive association when comparing UC at diagnosis vs. follow-up in cases, with a negative correlation between the effect sizes from the two analyses $(R=-0.92$; Supplementary Fig. 5b).

Collectively, these data suggest that between diagnosis and follow-up, the immune compartment undergoes the greatest amount of epigenetic response to treatment, with the epithelial and fibroblast compartments showing fewer changes. These findings are consistent with previous work ${ }^{17}$ reporting that DNAm changes in purified epithelial cells from mucosa persisted across two time-points. 
medRxiv preprint doi: https://doi.org/10.1101/2022.01.28.22269598; this version posted January 30, 2022. The copyright holder for this preprint (which was not certified by peer review) is the author/funder, who has granted medRxiv a license to display the preprint in perpetuity.

It is made available under a CC-BY-NC 4.0 International license .

\section{Biological relevance of the differentially methylated CpG sites in UC at disease course.}

In support of these patterns showing DNAm profiles at follow-up trending towards control levels, possibly due to inflammation-reducing treatment, gene ontology analysis on the $668 \mathrm{CpG}$ sites differing from UC at diagnosis to follow-up identified numerous biological processes related to immune function, including changes of B-cell/leukocyte activation and differentiation (Fig. 3a, Supplementary Table 4g). To gain further biological insight into the pathways related to DNAm changes in the immune compartment during treatment, we analyzed these $668 \mathrm{CpG}$ sites for association between DNAm and nearby gene expression (270 genes). In this analysis we compared changes in gene expression for each gene with DNAm changes at its associated $\mathrm{CpG}$ site across a matched cohort of UC patients $(\mathrm{n}=29)$ and observed that expression of 39 genes associated with DNAm at $42 \mathrm{CpG}$ sites $(P<0.05$; Supplementary

Table 4g). Differential expression analysis at diagnosis vs. follow-up ( $n=29$ matched samples) ${ }^{23}$ identified 6 of the 39 genes (FGD2, CRYL1, GXYLT2, PARP1, FOXN3, and ILIR2) as differentially expressed $(P<0.05$; Fig. 3b, Supplementary Table 4h). As an example, we highlight two CpG-gene pairs in Fig. 3c, which shows the relative levels of DNAm at CpG sites 1500 base pairs upstream from the transcription start site (TSS) of FGD2 and IL1R2 genes, and their corresponding gene expression level for the same UC subjects at diagnosis and follow-up.

To gain a finer-grained understanding of the immune compartment, we used an immune-subtype reference panel (see methods) to make cell-type composition estimates within this compartment breaking cell-counts into 7 parts (B-, CD8T-, CD4T-cells, monocytes, neutrophils, eosinophils, and nature killer cells). We identified significant changes in the cellular proportions of B-cells and CD4 T-cells between diagnosis and follow-up $(P<0.05$, Wilcoxon test, Supplementary Fig. 6), with decreases in B-cell and increases in T-cell proportions at follow-up. Although neutrophil abundance did not change significantly from diagnosis to follow-up, most of the significant changes in DNAm between diagnosis and follow-up (145 CpG sites) were inferred to be attributable to the neutrophil compartment (Supplementary Fig. 7; Supplementary Table 4i). We also observed at least $9 \mathrm{CpG}$ sites showing different DNAm patterns in 
medRxiv preprint doi: https://doi.org/10.1101/2022.01.28.22269598; this version posted January 30, 2022. The copyright holder for this preprint (which was not certified by peer review) is the author/funder, who has granted medRxiv a license to display the preprint in perpetuity.

It is made available under a CC-BY-NC 4.0 International license .

B-cells (Supplementary Fig. 7; Supplementary Table 4j). Thus, neutrophils, and to some extent Bcells, appear to be undergoing the largest amount of epigenetic change in the mucosa during UC treatment, at least as inferred from this model. Single-cell or purified cell analysis will be the most efficient method moving forward to confirm these model-based inferences.

\section{UC-specific rectal DNAm signatures at diagnosis correlate with disease severity defined by PUCAI.}

Next, as a proof-of-concept, we asked if DNAm could distinguish patients with UC based on their disease severity. A comparison of 44 mild UC $(10<$ PUCAI < 35), 80 moderate UC $(35<$ PUCAI < 65) and 87 severe UC patients (PUCAI > 65) across the entire $820 \mathrm{~K}$ CpG panel showed significant differences between mild vs moderate, and mild vs severe UC patients in PC1 (Supplementary Fig. 8). However, no differences were observed between moderate vs severe UC. The estimated cell proportions from mucosal DNAm profiles show no significant differences for either epithelial cell, fibroblasts, and immune cell across disease severity in UC (Supplementary Fig. 8). Consistent with this, our cell type specific EWAS among mild, moderate and severe UC patients did not identify any significant CpGs (data not shown). Therefore, to identify individual $\mathrm{CpG}$ sites that capture disease severity within each cell type, we grouped patients with moderate and severe UC $(n=167)$ and compared them to those with mild UC (n=44), revealing 46, 127 and 13 CpGs in epithelial, immune and fibroblast compartments, respectively (Supplementary Fig. 8b, Supplementary Tables 5-7). GO analysis of these sites did not establish strong evidence for enrichment of any biological processes at FDR $<0.05$.

We tested whether any of the cell-specific CpG sites (as a predictor) are associated with nearby gene expression (as an outcome). We observed that only one CpG site (cg10794399) from epithelial cells associated with AFF3 transcript abundance (Supplementary Table 5) and a few CpG sites from immune cells were associated with C6orf10, PKIB, TUB, KHDRBS3, ACTA2, IRX5, SHANK2, IGFBP6 genes (FDR < 0.05; Supplementary Table 6). However, none of these genes were differentially expressed in mild UC when compared to moderate and severe (data not shown). 
medRxiv preprint doi: https://doi.org/10.1101/2022.01.28.22269598; this version posted January 30, 2022. The copyright holder for this preprint (which was not certified by peer review) is the author/funder, who has granted medRxiv a license to display the preprint in perpetuity.

It is made available under a CC-BY-NC 4.0 International license .

Collectively, the cell-specific disease severity analysis on the rectal biopsy DNAm from UC at diagnosis indicated that epigenetically moderate and severe UC patients group together, whereas mild UC has a distinct epigenetic profile relative to moderate and severe UC as defined by PUCAI. On the other hand, we couldn't establish any evidence that these CpG sites are involved in nearby gene regulation or biological processes related to disease severity in UC.

Rectal DNAm signatures show potential for indicating colectomy risk. The total DNAm signatures were analyzed for signals indicating predisposition towards severe disease resulting in colectomy by year 2 post diagnosis. $\mathrm{PC} 1$ of the total $820 \mathrm{~K} \mathrm{CpG}$ sites showed a significant difference in the DNAm signatures between patients who would eventually undergo colectomy at 2 years post diagnosis with patients who did not (Supplementary Fig. 9). Similarly, significant differences in DNAm signatures amongst the three compartments, epithelial, immune and fibroblast were also observed between colectomy and no-colectomy. In total, 24 patients underwent colectomy in the 2 years after diagnosis, and while the "no colectomy" group showed improvements in epithelial $(P=0.01)$ and fibroblast $(P=$ 0.002) proportions along with a decrease in immune cell proportions at follow-up $(P=0.004)$ (a sign of mucosal healing and reduction of inflammation), the colectomy group showed no improvement in epithelial $(P=0.89)$ and fibroblast proportions $(P=0.49)$ and no decrease in the immune proportions (remaining elevated compared to "no colectomy" at follow-up; $P=0.80)(\mathrm{n}=175 ;$ Fig. 4a).

To identify genes whose DNAm patterns at diagnosis indicate the need for future colectomy, cell-type specific EWAS analysis was performed on non-colectomy UC patients $(n=175)$ vs UC patients who eventually underwent colectomy (n=24; Fig. 4b; Supplementary Fig. 10). We identified 89 CpG sites from the epithelial cells (Fig. 4b top panel; Supplementary Table 8), $257 \mathrm{CpG}$ sites from the immune cells (Fig. 4b middle panel and Supplementary Table 9), and 63 CpG sites coming from the fibroblast (Fig. 4b bottom panel and Supplementary Table 10) that were different between the colectomy vs. non-colectomy groups. GO analysis of UC colectomy $\mathrm{CpG}$ sites did not establish strong evidence for enrichment of any biological processes at FDR $<0.05$. 
medRxiv preprint doi: https://doi.org/10.1101/2022.01.28.22269598; this version posted January 30, 2022. The copyright holder for this preprint (which was not certified by peer review) is the author/funder, who has granted medRxiv a license to display the preprint in perpetuity.

It is made available under a CC-BY-NC 4.0 International license .

One of the 89 epithelial specific CpGs was associated with KCND2 expression, but we did not observe any association between expression of KCND2 and colectomy status. Similarly, 16 out of 257 immune-specific $\mathrm{CpG}$ sites were nominally associated with expression of 16 unique genes (Supplementary Table 9). Of the 16, only PFN4 was differentially expressed between colectomy and non-colectomy UC $(P=0.04)$. Lastly, one of the 63 fibroblast-specific CpGs (cg13569868 in FOXN3) was associated with significant expression differences, but there was no indication that expression of FOXN3 is associated with colectomy status in UC. Replication with a considerably larger samples size will be needed for a more convincing demonstration.

We further analyzed differences at diagnosis in the severe UC group by comparing those patients that eventually underwent colectomy at 2 years post diagnosis $(n=14)$ to those that did not $(n=60)$. The epithelial cell proportions were nominally decreased $(P=0.05)$ at diagnosis in colectomy severe UC patients when compared to non-colectomy severe UC patients (Supplementary Fig. 11a, top panel). In contrast, an increase in the immune and fibroblast proportions was observed for the colectomy group, but the differences did not reach statistical significance (Supplementary Fig. 11a, middle and bottom panels). Only $2 \mathrm{CpG}$ sites for epithelial and fibroblast cells were found by cell-specific EWAS analysis (Supplementary Fig. 11b, top and bottom panels; Supplementary Table 8,10), and $64 \mathrm{CpG}$ sites for immune cells (Supplementary Fig. 11b, middle panel; Supplementary Table 9). Using a subset of 44 severe UC patients that had both gene expression and DNAm data, we identified 4 of $64 \mathrm{CpG}$ sites from immune cells that were associated with the PBX3, RHOBTB1, ST3GAL1, and ZHX2 genes. Of these, ZHX2 was differentially expressed between colectomy severe UC and non-colectomy severe UC $(\mathrm{p}=$ 0.04). GO analysis of severe UC colectomy associated $\mathrm{CpG}$ sites did not establish strong evidence for enrichment of any biological processes at FDR $<0.05$.

Collectively, our DNAm estimated cell proportions results suggest that at follow-up, a lack of change in methylation signals with poor indicators at diagnosis (low epithelial, high immune) is a potential clinical indicator for colectomy. Also, joint cell-specific differential methylation and gene 
medRxiv preprint doi: https://doi.org/10.1101/2022.01.28.22269598; this version posted January 30, 2022. The copyright holder for this preprint (which was not certified by peer review) is the author/funder, who has granted medRxiv a license to display the preprint in perpetuity.

It is made available under a CC-BY-NC 4.0 International license .

expression analysis identified several potential epigenetic sites/genes from immune cells as colectomyrisk biomarkers or possible therapeutic target.

Clinical relevance of differentially methylated CpG sites in UC. The distinction between methylation signatures in UC at diagnosis and controls suggests that a diagnostic potential exists in these values that can be leveraged for patient stratification. Interestingly, the identified UC specific rectal biopsy CpG sites from epithelial, immune cells, and fibroblasts measured from training dataset, could indeed distinguish UC patients from controls in an independent validation dataset, with 96\% accuracy (AUC $=0.96$ ); Supplementary Fig. 12). Future studies on DNAm profiled from isolated epithelial, immune cells, and fibroblasts from UC patient's rectal biopsies are required to establish the diagnostic potential of our cellspecific methylation signatures. On the other hand, we were not able to establish any evidence that the rectal biopsy DNAm profiles predict disease progression or outcome in UC. An experimental design more directed at contrasting UC patients who undergo colectomy at follow-up from non-colectomy UC patients would have more power to find such a signature.

\section{Discussion}

In this study, we used a treatment naïve inception UC cohort in which biospecimens underwent multiomic analysis at baseline and follow-up. Taking advantage of this inception cohort with extensive prospective clinical meta-data, we estimated DNAm-based cell type proportions in the human rectal mucosa - epithelial, immune and fibroblast compartments - and examined DNAm differences in each of these compartments at the time of diagnosis and during the course of UC.

We first showed that within each compartment, UC-specific epigenetic changes are disturbed at diagnosis. We next found that after treatment, overall cell proportions, and many of the cell-specific methylation patterns moved closer to levels seen in controls. This pattern was most pronounced in 
immune cells and is hardly surprising since current treatment primarily targets the immune system and clearly its effects are most direct and observable in this compartment. Further analysis showed significant differences in estimated cell proportions at follow-up between individuals with mild UC and the moderate/severe group. There were no experiment-wide significant differences in DNA methylation level between moderate and severe disease. On the other hand, there were widespread methylation differences at follow-up between those with ongoing, severe disease who would soon need colectomy, and those who would not. Remarkably, DNAm signatures observed in the rectal mucosa at diagnosis could also distinguish patients destined to need a colectomy within 2 years and those who did not. However, given that differential expression for PFN4 was only nominally significant, replication attempts of these patterns in larger samples are warranted.

The epithelial barrier is the front-line defense against invading microbes, toxins, and other luminal contents, but also provides selective transport of nutrients and other beneficial substances that maintain homeostasis and carries significant inflammatory consequences to underlying mucosa upon its malfunction and degradation. The lack of epigenetic changes in the epithelial and fibroblast cells following treatment is of concern to mucosal healing. Notably, we observed that at least $25 \%$ of the epithelial derived $\mathrm{CpG}$ sites (889 out of 3504) changing during UC are consistent with a previously published study that compared purified epithelial cell methylation patterns between UC patients and controls $^{17}$. Damage and erosion of the intestinal epithelium is a hallmark characteristic of UC, and the large number of epithelial-specific $\mathrm{CpG}$ sites affected at diagnosis indicates either a response to external stimuli potentiating the disease or a response to the damage that the body is trying to repair. In fact, in the study of epithelial-derived organoids described in the Introduction, at least $25 \%$ of the genes (124 out of 488) associated with epithelial derived $\mathrm{CpG}$ sites were also observed to be differentially expressed in $\mathrm{UC}^{17}$, supporting a relationship between changing DNAm and gene transcription in the epithelium during UC. Our observation of decreased epithelial proportions based on changes in DNAm signals, with a corresponding increase in immune cell abundance, is in line with the well-documented biological 
consequences of UC. Pathway analysis of the genes influenced by the significantly changing CpG sites showed changes in pathways regulating cell migration, lipid metabolism, small GTPase signaling and wound repair/healing, suggesting that the changes in DNAm in turn influence nearby genes and processes that are critically involved in restitution and repair ${ }^{33-36}$.

Fibroblasts originating from the mesenchymal compartment are responsible for maintaining the extracellular milieu that provides structural stability and regulatory growth and differentiation signals for the epithelium ${ }^{37-39}$. The decrease in proportion of this cellular compartment further correlates with symptoms of UC, but this was the one compartment that looked most similar in comparison to control abundance at follow-up. The epigenetic findings here provide new targets that should be considered for correcting UC related epigenetic changes that could promote mucosal healing. For example, UBE2G1 detected in fibroblasts was found to be hypomethylated and did not revert after treatment, and is a known IBD marker ${ }^{40}$. UBE2G1 is ubiquitin conjugating enzyme involved in degradation of short-lived proteins and known to have disease implications when its functionality is perturbed ${ }^{41-43}$. Further, whether therapeutic changes in the fibroblasts enhanced their immunosuppressive effects and facilitated a decrease in immune cell proportion was not entirely clear, but a reversion of many of the fibroblasts' CpG signatures to non-IBD status suggested this possibility.

Clearance of the immune response by current IBD treatments (anti-TNF as an example) has long been appreciated as the standard of care for IBD and was exemplified in our DNAm analysis where healing was associated with a decrease in mucosal immune proportions and reversion of many of the immunespecific CpG sites back to non-IBD signatures. Interestingly, FOXP1 ${ }^{44}, I L 23 R^{45-48}, C C R 9^{49,50}$ have been documented to play a role in IBD, and here their corresponding $\mathrm{CpG}$ loci were found to maintain diseasespecific DNAm signatures after treatment. The CCR9/CCL25 signaling axis is responsible for leukocyte trafficking to the gut and our data may reflect epigenetic changes during UC that are associated with the activation and recruitment of immune cells from the peripheral blood into the intestinal mucosa, consequentially sustaining inflammatory conditions and prolonging or worsening the disease. New 
targeted therapies that can offset epigenetic effects regulating $C C R 9$ may show improved resolution of the inflammatory response ${ }^{50}$.

Additionally, our study has revealed some important cell- and disease-severity specific findings that were not reported in previous literature. In our previous study, we reported that peripheral blood DNAm signatures in IBD associate with the degree of inflammation, but do not predict/characterize disease in the gut. In the current study, utilizing samples provided by the longitudinal UC patients from PROTECT cohort, we were able to address this question, demonstrating that the DNAm patterns from actual diseased tissues reflect the nature of disease rather than the inflammation status. This is further supported by our comparative analysis of cell-specific EWAS indicating that only 9 sites from both epithelium and immune cells, and 4 sites from fibroblasts, overlap with our previous total peripheral blood DNAm sites ${ }^{16}$. Unlike blood DNAm, the rectal tissue DNAm, particularly epithelial / mesenchymal tissue DNAm, do not revert back to normal levels. While contrasts between mild and moderate UC were largely difficult to interpret, differences between individuals requiring early colectomy and those with less severe disease were more pronounced. Methylation patterns at diagnosis seem to predict which patients are most likely to progress to colectomy after two years post treatment, and methylation and cell-composition patterns which fail to revert towards controls at follow-up are especially good predictors of who will require an early colectomy.

Our study is not without limitations. Our analysis was based on correlating clinical parameters with only one disease site (rectum), and the estimated cell proportions and identity are very much model-based estimates that should be confirmed with more direct experimentation approaches as performed in the previous single-cell or purified cell studies ${ }^{9,17,51,52}$. The model we employed to decompose mucosal data (comprised of numerous cell types) is believed to be well powered to distinguish three main cellular lineages (epithelial, immune and fibroblasts), but both imprecision in the model estimates as well as loss of sub-type resolution is unavoidable. While our study may be the most cutting-edge analysis that could 
be done on these tissues when collected at this sample size, we expect large scale-single cell analysis will confirm or reject our inferences in the foreseeable future.

In summary, we show that cell type-specific epigenetic changes are taking place in the rectal mucosa during the course of UC, and these changes are associated with disease severity and outcome. Further, our data also strongly suggest that, in IBD, we should focus studying the relevant tissue for DNAm and for other molecular signatures rather than blood. Based on our findings, we speculate that individuals who do not sufficiently respond to current therapies, targeting epithelial genes with barrier function, perhaps by attempting to revert methylation patterns to control levels, may improve mucosal healing.

\section{Methods:}

Overall study participants. The cases used for analysis here are a subset of the PROTECT UC cohort. PROTECT is a multicenter inception cohort with a total of 431 treatment naïve UC patients from 29 centers in the USA and Canada. This cohort was prospectively followed for at least 2 years with rectal biopsy collection at diagnosis (before treatment) and subsequent follow-up (treatment period from 8 weeks to 2 years; follow-up; $n=73$ ). Details regarding inclusion / exclusion criteria, study protocol, approvals, and other clinical parameters assessed have been reported previously ${ }^{21,22}$. Based on the availability of the rectal tissue DNA, 211 pediatric UC patients from the PROTECT cohort, aged 4-17 years old, were used. Out of the 211 had baseline rectal DNA availability, 73 of them also had follow-up rectal tissue DNA and were used. All 73 patient follow-up samples were collected as clinically indicated during the follow-up visits between 8 weeks to 2 years. All 73 patients received one or more treatment(s) prior to follow-up, described in detail in Hyams et $\mathrm{al}^{21,22}$. The UC diagnosis was based on conventional clinical, endoscopic, and histological parameters. For non-IBD controls, we used age- and gendermatched rectal biopsy genomic DNA samples from 85 RISK participants (RISK is described elsewhere ${ }^{20}$ ) that had no histologic or endoscopic inflammation and remained asymptomatic during the disease course. Both the PROTECT and RISK studies were approved by the Institutional Review Boards at each of the 
medRxiv preprint doi: https://doi.org/10.1101/2022.01.28.22269598; this version posted January 30, 2022. The copyright holder for this preprint (which was not certified by peer review) is the author/funder, who has granted medRxiv a license to display the preprint in perpetuity.

It is made available under a CC-BY-NC 4.0 International license .

participating RISK and PROTECT sites. The same sites in North America participated in both the PROTECT and RISK studies. All relevant ethical regulations for work on human participants have been met and conducted in accordance with the criteria set by the Declaration of Helsinki. Informed consent was obtained from the parents of all study participants. .

Quantification of genome-wide DNAm. Rectal biopsy genomic DNA was extracted using the AllPrep DNA/RNA Mini Kit (Qiagen, Valencia, CA), and 500ng of DNA was subjected to bisulfite treatment using EZ DNAm-GoldTM Kits (Zymo Research, Irvine, CA). MethylationEPIC BeadChip (Illumina, San Diego, CA) was used to quantify genome-wide DNAm differences across $~ 850,000$ genome-wide CpG sites ${ }^{53}$. The R package $\mathrm{CpGassoc}^{54}$ was used to perform the initial quality control (QC). CpG sites called with low signal or low confidence (detection $P>0.05$ ) or with data missing for greater than $10 \%$ of samples were removed, and samples with data missing or called with low confidence for greater than $10 \%$ of $\mathrm{CpG}$ sites were removed. Probes mapping to multiple locations were also removed ${ }^{55}$. After QC, a total of $\sim 820,000$ probes and 369 samples ( 85 non-IBD controls, 211 UC samples at diagnosis, and 73 samples from follow-up) remained. Beta values $(\beta)$ were calculated for each $\mathrm{CpG}$ site as the ratio of methylated (M) to the sum of methylated and unmethylated (U) signals: $\beta=M /(M+U)$. Signal intensities were then normalized using the module beta-mixture quantile dilation (BMIQ) ${ }^{56}$ to account for the probe type bias. These normalized signal intensities were used to perform principal component analysis to further identify sample outliers.

Estimating the cell proportions of rectal biopsy tissues. The R/Bioconductor-package EpiDISH ${ }^{24}$ was used to estimate cell type proportions through deconvolution of our bulk DNAm data derived from rectal tissue. Estimation was based on two reference panels: (i) an epithelial, immune and fibroblast -specific reference panel and (ii) another immune subtype cells reference panel that can also map the data to 7 immune cell types; B-cells, CD4+ T-cells, CD8+ T-cells, NK-cells, monocytes, neutrophils, and eosinophils. These estimated cell type proportions were used as covariates in all DNAm analyses to adjust for differences in DNAm due to between-sample differences in cellular composition. 
medRxiv preprint doi: https://doi.org/10.1101/2022.01.28.22269598; this version posted January 30, 2022. The copyright holder for this preprint (which was not certified by peer review) is the author/funder, who has granted medRxiv a license to display the preprint in perpetuity.

It is made available under a CC-BY-NC 4.0 International license .

Genotyping and data processing. Peripheral blood DNA samples of 296 cases and controls with DNAm data were genotyped using the UK Biobank array, and 850,000 genotypes were called using the Axiom Suite software. All subjects had call rates $>95 \%$ and consistent gender records with the clinical data. All quality control procedures were performed in PLINK ${ }^{57}$. Principal components were computed based on a pruned version "--hwe 0.001 --maf 0.2 --geno 0.01 --indep-pairwise 5050.2 " of the data set consisting of 58,237 LD-independent SNPs $\left(r^{2}<0.1\right)$. We used the first 5 genotype-based principal components to control for population stratification in all analyses.

DNAm association with UC at diagnosis. To identify $\mathrm{CpG}$ sites associated with UC at diagnosis, we performed a case-control EWAS on 211 UC patients at diagnosis compared to 85 non-IBD controls. UCassociated methylation changes in rectal tissue regardless of cell type were first profiled using the $\mathrm{R}$ package CpGassoc ${ }^{54}$. Briefly, DNAm was regressed on disease status ( 0 for control, 1 for UC) with age, gender, epithelial and fibroblast cell proportions, and the first five genotype-based principal components as covariates in the model.

Cell-specific methylation association with UC at diagnosis. We next used the CellDMC function from the EpiDISH ${ }^{24}$ package to identify sets of $\mathrm{CpGs}$ that show a cell-type specific association with UC. We performed cell-specific EWAS within the epithelial, immune and fibroblasts to test for association between UC and methylation at the $\sim 820,000$ sites that passed QC. DNAm at each CpG was regressed on disease status ( 0 for control, 1 for UC) and age, gender, and the first five genotype-based principal components were included as covariates in the model, along with covariates for DNAm-based estimates of cellular proportions, and an interaction term between UC and cellular proportion to identify cellspecific signal. We identified significant CpGs within each EWAS using the Benjamini-Hochberg false discovery rate criterion $(\mathrm{FDR}<0.05)$.

Cell-specific methylation association with UC at diagnosis versus follow-up. To assess longitudinal changes in DNAm in patients with UC, we compared the methylation levels in rectal biopsy samples 
obtained at diagnosis and follow-up ( $\mathrm{n}=73$; from 8 weeks to 2 years). Age was recalculated for the follow-up samples based upon their time of visit after diagnosis. In the cell-specific EWAS, DNAm was regressed on disease course ( 0 for at diagnosis, 1 for at follow-up), and age, gender, and the first five genotype-based principal components were included as covariates in the model, along with the covariates and interactions for cell type proportion. To account for the two time points from each patient, representing DNAm levels at diagnosis and follow-up, we included fixed effect covariates for subject ID. To identify CpG sites associated with UC during treatment, we performed a similar cell-specific EWAS comparing diagnosis vs follow-up within the same samples $(n=73)$.

Gene Ontology (GO) biological process enrichment analysis. Gene ontology (GO) for biological process enrichment analysis was performed for genes annotated to our UC associated CpG sites by the R/Bioconductor package missMethyl ${ }^{58}$. Genes with more $\mathrm{CpG}$ probes on the MethylationEPIC array are more likely to have differentially methylated CpGs, which could introduce potential bias when performing pathway enrichment analysis. The gometh function implemented in missMethyl considers the varying number of differentially methylated CpGs by computing a prior probability for each gene based on the gene length and the number of CpGs probed per gene on the array. Similarly, the GO biological process enrichment analysis for UC associated genes that are associated to UC associated CpGs was performed by using Toppgene ${ }^{59}$.

Analysis of DNAm and gene expression. Differential gene expression analysis was performed on a subset of patients from whom both gene expression and DNAm data was available from the rectal mucosa $(\mathrm{n}=119)$. Gene expression was previously measured using TruSeq Illumina mRNAseq (20 controls and 211 UC samples) ${ }^{23}$ or Lexogen 3'UTR mRNAseq (39 UC at diagnosis and a matched subset of the same 39 UC patients' sampled at 52 week follow-up) ${ }^{60}$. More details on RNA sequencing, data processing and QC are described elsewhere ${ }^{23,60}$. 
medRxiv preprint doi: https://doi.org/10.1101/2022.01.28.22269598; this version posted January 30, 2022. The copyright holder for this preprint (which was not certified by peer review) is the author/funder, who has granted medRxiv a license to display the preprint in perpetuity.

It is made available under a CC-BY-NC 4.0 International license .

CpG sites associated with disease status, disease course, disease severity, or colectomy status in the EWAS were further tested for association with expression of genes as annotated by Illumina. In total we used data from 119 patients with UC who had both DNAm and TruSeq Illumina mRNAseq gene expression profiles ${ }^{23}$. DNAm values were regressed on gene expression counts using the $\operatorname{lm}()$ R function, with age, gender and the first five genotype-based principal components included as covariates in the model. A false discovery rate criterion (Benjamini-Hochberg FDR <.05) was used to define a set of significant CpG-gene pairs.

Differential gene expression analysis on disease status, disease severity, and colectomy status. We also performed a targeted differential expression analysis of genes annotated to the $\mathrm{CpG}$ sites identified in the EWAS of disease status, disease course, disease severity and/or colectomy status. The TruSeq Illumina mRNAseq dataset ${ }^{23}(\mathrm{n}=119)$ was used to identify genes differentially expressed between disease status, disease severity and/or colectomy status. Similarly, the Lexogen 3'UTR mRNAseq data was analyzed to identify genes differentially expressed for CpGs associated to UC at disease course. The DEseq2 package was used to perform the differential expression analysis. Briefly, gene expression values were regressed on disease status, disease severity, or colectomy status with age and gender adjusted as covariates in the model using the default normalization method. DE genes were identified using either nominal p-value $<0.05$ and fold change $(\mathrm{FC})>1.2$.

\section{Random forest classification}

The entire dataset at diagnosis $(\mathrm{n}=296)$ was divided into a $75 \%$ training (64 controls and 158 UC cases) and a $25 \%$ validation set (21 controls and $53 \mathrm{UC}$ cases). The CellDMC was performed only on training dataset samples and the UC specific $\mathrm{CpG}$ sites across all three cell-types were identified. A RandomForest (RF) model constructed using the identified UC specific CpG sites of training dataset using randomForest package ${ }^{61}$ in $\mathrm{R}$ with default parameters. The trained RF model was tested using the test dataset samples to test the prediction performance of the defined model. Accuracies (ACC) and area 
medRxiv preprint doi: https://doi.org/10.1101/2022.01.28.22269598; this version posted January 30, 2022. The copyright holder for this preprint (which was not certified by peer review) is the author/funder, who has granted medRxiv a license to display the preprint in perpetuity.

It is made available under a CC-BY-NC 4.0 International license .

under the curve (AUC) were calculated by comparing of actual labels to predicted labels of test set class, separately for cases and controls.

Fig. 1: DNAm and corresponding gene signatures associated with UC at diagnosis: (a) Comparison of estimated cell proportions for epithelial, immune cells and fibroblasts between rectal biopsies from UC patients (at diagnosis) and controls. P-values are shown from the Wilcoxon test. (b) Cell-specific epigenome-wide DNAm analysis (EWAS) comparing UC patients to controls. The blue line represents significant differential methylation at FDR $<0.05$, and the red line represents Bonferroni-adjusted genome-wide significance $(P<1 \mathrm{e}-08)$. (c) The volcano plot shows differentially expressed genes that are associated with cell specific $\mathrm{CpG}$ sites in UC for all three cell types. $\mathrm{x}$-axis shows $\log 2 \mathrm{FC}$ and $\mathrm{y}$ - axis shows the negative log p-value detected for each gene in DE analysis. (d) The lollipop diagram shows Gene Ontology (GO) biological processes identified as enriched in sets of differentially methylated CpG sites (blue) and differentially expressed genes in UC. Y- axis shows the number of CpGs and genes detected for each GO term.

Fig. 2: Longitudinal profiling of DNAm in UC patients at during the disease. (a) The boxplots show the rectal biopsy DNAm estimated cell proportions for epithelial, immune and fibroblast compared among controls $(n=85), U C$ at diagnosis $(n=211)$ and UC at Follow-up $(n=73)$. P-values are from the Wilcoxon test. (b) Cell-specific EWAS analysis shows differentially methylated sites between UC at diagnosis and UC at follow-up (paired samples, $n=73$ ) for all three major cell types. The blue line represents the sites significant at FDR $<0.05$, and the red line represents the sites significant at epigenome-wide $P<1 \mathrm{e}-08$. (c) The effect sizes for all the UC associated sites from all three types epithelial ( $\mathrm{n}=3504 \mathrm{CpG}$ sites) and fibroblast ( $\mathrm{n}=910)$ and immune cells $(\mathrm{n}=2279)$ of UC at diagnosis i.e., UC at diagnosis vs Controls ( $\mathrm{x}-$ axis) were compared to UC at disease course i.e., UC at diagnosis vs follow-up (y-axis). In the immune sub-panel, maroon dots represent the $96 \mathrm{CpG}$ sites that reached significance after multiple test corrections on p-values of $2279 \mathrm{CpGs}$ in UC at disease course (FDR < 0.05). (d) The effect sizes for all the CpG sites 
medRxiv preprint doi: https://doi.org/10.1101/2022.01.28.22269598; this version posted January 30, 2022. The copyright holder for this preprint (which was not certified by peer review) is the author/funder, who has granted medRxiv a license to display the preprint in perpetuity.

It is made available under a CC-BY-NC 4.0 International license .

associated with disease course i.e., UC at diagnosis vs follow-up (y-axis) from only immune cells ( $\mathrm{n}=668$ ) were compared to UC at diagnosis i.e., UC at diagnosis vs Controls (x-axis). In the sub-panel, maroon dots represent the $154 \mathrm{CpG}$ sites that reached significance after multiple test corrections on p-values of 668 CpGs in UC at diagnosis (FDR < 0.05).

Fig. 3: Regulatory importance of the differentially methylated CpG sites in UC at disease course. (a) The lollipop diagram shows Gene Ontology (GO) biological processes identified for 668 differentially methylated CpG sites (blue) from immune cells. Y- axis shows the number of CpGs detected in each GO term. (b) The volcano plot shows differentially expressed genes that are associated with immune cell specific $\mathrm{CpG}$ sites in UC during the course of the disease. $\mathrm{x}$-axis shows $\log 2 \mathrm{FC}$ and $\mathrm{y}$ - axis shows the negative $\log$ p-value detected for each gene in DE analysis. (c) Boxplots depicting the methylation proportions of UC at diagnosis and during follow-up (matched sample, $n=29$, that contains both DNAm and gene expression profiles) at the two CpG sites located TSS1500 to the nearby gene, and the corresponding gene expression values are plotted. Y-axis shows DNAm values and log of read counts representing methylation and gene expression, respectively.

Fig. 4: DNAm signatures at diagnosis associated with colectomy at 2 years. (a) Comparison of estimated cell proportions for epithelial, immune cells and fibroblasts obtained from rectal biopsies at diagnosis compared between colectomy and non-colectomy groups. P-values are from the Wilcoxon test. (b) Cell-specific epigenome-wide DNAm analysis (EWAS) comparing UC patients who underwent colectomy at two years $(n=24)$ to non-colectomy UC patients $(n=175)$. The blue line represents significant differential methylation at FDR $<0.05$, and the red line represents Bonferroni-adjusted genome-wide significance $(P<1 \mathrm{e}-08)$. 
medRxiv preprint doi: https://doi.org/10.1101/2022.01.28.22269598; this version posted January 30, 2022. The copyright holder for this preprint (which was not certified by peer review) is the author/funder, who has granted medRxiv a license to display the preprint in perpetuity. It is made available under a CC-BY-NC 4.0 International license. 


\section{References:}

1 Alatab, S. et al. The global, regional, and national burden of inflammatory bowel disease in 195 countries and territories, 1990-2017: a systematic analysis for the Global Burden of Disease Study 2017. The Lancet gastroenterology \& hepatology 5, 17-30 (2020).

2 Hedin, C. et al. The pathogenesis of extraintestinal manifestations: implications for IBD research, diagnosis, and therapy. Journal of Crohn's and Colitis 13, 541-554 (2019).

3 Liu, J. Z. et al. Association analyses identify 38 susceptibility loci for inflammatory bowel disease and highlight shared genetic risk across populations. Nat Genet 47, 979986, doi:10.1038/ng.3359 (2015).

4 de Lange, K. M. et al. Genome-wide association study implicates immune activation of multiple integrin genes in inflammatory bowel disease. Nat Genet 49, 256-261, doi:10.1038/ng.3760 (2017).

5 Venkateswaran, S. et al. Enhanced Contribution of HLA in Pediatric Onset Ulcerative Colitis. Inflamm Bowel Dis 24, 829-838, doi:10.1093/ibd/izx084 (2018).

6 Kellermayer, R. "Omics" as the filtering gateway between environment and phenotype: The inflammatory bowel diseases example. American Journal of Medical Genetics Part A 152, 3022-3025 (2010).

7 Saito, S. et al. DNA methylation of colon mucosa in ulcerative colitis patients: correlation with inflammatory status. Inflamm Bowel Dis 17, 1955-1965, doi:10.1002/ibd.21573 (2011).

8 Taman, H. et al. Genome-wide DNA Methylation in Treatment-naive Ulcerative Colitis. J Crohns Colitis 12, 1338-1347, doi:10.1093/ecco-jcc/jjy117 (2018).

9 Barnicle, A., Seoighe, C., Greally, J. M., Golden, A. \& Egan, L. J. Inflammationassociated DNA methylation patterns in epithelium of ulcerative colitis. Epigenetics 12, 591-606, doi:10.1080/15592294.2017.1334023 (2017).

10 Ventham, N. T. et al. Integrative epigenome-wide analysis demonstrates that DNA methylation may mediate genetic risk in inflammatory bowel disease. Nat Commun 7 , 13507, doi:10.1038/ncomms13507 (2016).

11 Karatzas, P. S., Gazouli, M., Safioleas, M. \& Mantzaris, G. J. DNA methylation changes in inflammatory bowel disease. Ann Gastroenterol 27, 125-132 (2014).

12 McDermott, E. et al. DNA Methylation Profiling in Inflammatory Bowel Disease Provides New Insights into Disease Pathogenesis. J Crohns Colitis 10, 77-86, doi:10.1093/ecco-jcc/jjv176 (2016).

13 Li Yim, A. Y. F. et al. Peripheral blood methylation profiling of female Crohn's disease patients. Clin Epigenetics 8, 65, doi:10.1186/s13148-016-0230-5 (2016).

14 Nimmo, E. R. et al. Genome-wide methylation profiling in Crohn's disease identifies altered epigenetic regulation of key host defense mechanisms including the Th17 pathway. Inflamm Bowel Dis 18, 889-899, doi:10.1002/ibd.21912 (2012).

15 Farh, K. K. et al. Genetic and epigenetic fine mapping of causal autoimmune disease variants. Nature 518, 337-343, doi:10.1038/nature13835 (2015).

16 Somineni, H. K. et al. Blood-Derived DNA Methylation Signatures of Crohn's Disease and Severity of Intestinal Inflammation. Gastroenterology 156, 2254-2265 e2253, doi:10.1053/j.gastro.2019.01.270 (2019). 
17 Howell, K. J. et al. DNA methylation and transcription patterns in intestinal epithelial cells from pediatric patients with inflammatory bowel diseases differentiate disease subtypes and associate with outcome. Gastroenterology 154, 585-598 (2018).

18 Harris, R. A. et al. DNA methylation-associated colonic mucosal immune and defense responses in treatment-naïve pediatric ulcerative colitis. Epigenetics 9, 1131-1137 (2014).

19 Kraiczy, J. et al. DNA methylation defines regional identity of human intestinal epithelial organoids and undergoes dynamic changes during development. Gut 68, 49-61 (2019).

20 Kugathasan, S. et al. Prediction of complicated disease course for children newly diagnosed with Crohn's disease: a multicentre inception cohort study. Lancet 389, 17101718, doi:10.1016/S0140-6736(17)30317-3 (2017).

21 Hyams, J. S. et al. Factors associated with early outcomes following standardised therapy in children with ulcerative colitis (PROTECT): a multicentre inception cohort study. Lancet Gastroenterol Hepatol 2, 855-868, doi:10.1016/S2468-1253(17)30252-2 (2017).

22 Hyams, J. S. et al. Clinical and biological predictors of response to standardised paediatric colitis therapy (PROTECT): a multicentre inception cohort study. Lancet 393, 1708-1720, doi:10.1016/S0140-6736(18)32592-3 (2019).

23 Haberman, Y. et al. Ulcerative colitis mucosal transcriptomes reveal mitochondriopathy and personalized mechanisms underlying disease severity and treatment response. Nat Commun 10, 38, doi:10.1038/s41467-018-07841-3 (2019).

24 Zheng, S. C., Breeze, C. E., Beck, S. \& Teschendorff, A. E. Identification of differentially methylated cell types in epigenome-wide association studies. Nat Methods 15, 1059-1066, doi:10.1038/s41592-018-0213-x (2018).

25 Strober, W., Fuss, I. \& Mannon, P. The fundamental basis of inflammatory bowel disease. J Clin Invest 117, 514-521, doi:10.1172/jci30587 (2007).

26 Alipour, M. et al. Mucosal Barrier Depletion and Loss of Bacterial Diversity are Primary Abnormalities in Paediatric Ulcerative Colitis. Journal of Crohn's and Colitis 10, $462-$ 471, doi:10.1093/ecco-jcc/jjv223 (2015).

27 Fournier, B. M. \& Parkos, C. A. The role of neutrophils during intestinal inflammation. Mucosal Immunol 5, 354-366, doi:10.1038/mi.2012.24 (2012).

28 Matthews, J. D. et al. Redox control of Cas phosphorylation requires Abl kinase in regulation of intestinal epithelial cell spreading and migration. Am J Physiol Gastrointest Liver Physiol 311, G458-465, doi:10.1152/ajpgi.00189.2016 (2016).

29 Birkl, D. et al. TNF $\alpha$ promotes mucosal wound repair through enhanced platelet activating factor receptor signaling in the epithelium. Mucosal Immunol 12, 909-918, doi:10.1038/s41385-019-0150-8 (2019).

$30 \mathrm{Li}$, Y. et al. Disease-related expression of the IL6/STAT3/SOCS3 signalling pathway in ulcerative colitis and ulcerative colitis-related carcinogenesis. Gut 59, 227-235, doi:10.1136/gut.2009.184176 (2010).

31 Keshavarzian, A. et al. Increased interleukin-8 (IL-8) in rectal dialysate from patients with ulcerative colitis: evidence for a biological role for IL-8 in inflammation of the colon. Am J Gastroenterol 94, 704-712, doi:10.1111/j.1572-0241.1999.00940.x (1999).

32 Turner, D. et al. Development, validation, and evaluation of a pediatric ulcerative colitis activity index: a prospective multicenter study. Gastroenterology 133, 423-432 (2007).

33 Matthews, J. D. et al. Proteomic analysis of microbial induced redox-dependent intestinal signaling. Redox Biol 20, 526-532, doi:10.1016/j.redox.2018.11.011 (2019). 
medRxiv preprint doi: https://doi.org/10.1101/2022.01.28.22269598; this version posted January 30, 2022. The copyright holder for this preprint (which was not certified by peer review) is the author/funder, who has granted medRxiv a license to display the preprint in perpetuity.

It is made available under a CC-BY-NC 4.0 International license.

34 Miyoshi, H. et al. Prostaglandin E2 promotes intestinal repair through an adaptive cellular response of the epithelium. Embo j 36, 5-24, doi:10.15252/embj.201694660 (2017).

35 Leeb, S. N. et al. Reduced migration of fibroblasts in inflammatory bowel disease: role of inflammatory mediators and focal adhesion kinase. Gastroenterology 125, 1341-1354, doi:10.1016/j.gastro.2003.07.004 (2003).

36 Sommer, K. et al. Intestinal Mucosal Wound Healing and Barrier Integrity in IBDCrosstalk and Trafficking of Cellular Players. Front Med (Lausanne) 8, 643973, doi:10.3389/fmed.2021.643973 (2021).

37 Göke, M., Kanai, M. \& Podolsky, D. K. Intestinal fibroblasts regulate intestinal epithelial cell proliferation via hepatocyte growth factor. American Journal of Physiology-

Gastrointestinal and Liver Physiology 274, G809-G818, doi:10.1152/ajpgi.1998.274.5.G809 (1998).

38 Simo, P. et al. Dual and asynchronous deposition of laminin chains at the epithelialmesenchymal interface in the gut. Gastroenterology 102, 1835-1845, doi:10.1016/00165085(92)90303-g (1992).

39 Pastuła, A. \& Marcinkiewicz, J. Cellular Interactions in the Intestinal Stem Cell Niche. Archivum Immunologiae et Therapiae Experimentalis 67, 19-26, doi:10.1007/s00005018-0524-8 (2019).

40 Alsobrook, J. I. et al. Novel Genomic Biomarkers That Differentiate Between Inflammatory Bowel Disease and Normal Patients Using Peripheral Blood Specimens: 1125. Official journal of the American College of Gastroenterology|ACG 103, S439 (2008).

41 Filatova, E. V. et al. Expression analysis of genes of ubiquitin-proteasome protein degradation system in MPTP-induced mice models of early stages of Parkinson's disease. Dokl Biochem Biophys 456, 116-118, doi:10.1134/s1607672914030107 (2014).

42 Lu, G. et al. UBE2G1 governs the destruction of cereblon neomorphic substrates. Elife 7, doi:10.7554/eLife.40958 (2018).

43 Evangelou, M. et al. A method for gene-based pathway analysis using genomewide association study summary statistics reveals nine new type 1 diabetes associations. Genet Epidemiol 38, 661-670, doi:10.1002/gepi.21853 (2014).

44 Ren, J. et al. Foxp1 is critical for the maintenance of regulatory T-cell homeostasis and suppressive function. PLoS Biol 17, e3000270, doi:10.1371/journal.pbio.3000270 (2019).

45 Sivanesan, D. et al. IL23R (Interleukin 23 Receptor) Variants Protective against Inflammatory Bowel Diseases (IBD) Display Loss of Function due to Impaired Protein Stability and Intracellular Trafficking. J Biol Chem 291, 8673-8685, doi:10.1074/jbc.M116.715870 (2016).

46 Duerr, R. H. et al. A genome-wide association study identifies IL23R as an inflammatory bowel disease gene. Science 314, 1461-1463, doi:10.1126/science.1135245 (2006).

47 Sun, R., Hedl, M. \& Abraham, C. IL23 induces IL23R recycling and amplifies innate receptor-induced signalling and cytokines in human macrophages, and the IBD-protective IL23R R381Q variant modulates these outcomes. Gut 69, 264-273, doi:10.1136/gutjnl2018-316830 (2020).

48 Kim, S. W. et al. Genetic polymorphisms of IL-23R and IL-17A and novel insights into their associations with inflammatory bowel disease. Gut 60, 1527-1536, doi:10.1136/gut.2011.238477 (2011). 
medRxiv preprint doi: https://doi.org/10.1101/2022.01.28.22269598; this version posted January 30, 2022. The copyright holder for this preprint (which was not certified by peer review) is the author/funder, who has granted medRxiv a license to display the preprint in perpetuity.

It is made available under a CC-BY-NC 4.0 International license .

49 Wendt, E. \& Keshav, S. CCR9 antagonism: potential in the treatment of Inflammatory Bowel Disease. Clin Exp Gastroenterol 8, 119-130, doi:10.2147/ceg.S48305 (2015).

$50 \quad$ Koenecke, C. \& Förster, R. CCR9 and inflammatory bowel disease. Expert Opin Ther Targets 13, 297-306, doi:10.1517/14728220902762928 (2009).

51 Lin, Z. et al. Identification of disease-associated DNA methylation in B cells from Crohn's disease and ulcerative colitis patients. Digestive diseases and sciences 57, 31453153 (2012).

52 Li Yim, A. Y. et al. Whole-genome DNA methylation profiling of CD14+ monocytes reveals disease status and activity differences in Crohn's disease patients. Journal of clinical medicine 9, 1055 (2020).

53 Moran, S., Arribas, C. \& Esteller, M. Validation of a DNA methylation microarray for $850,000 \mathrm{CpG}$ sites of the human genome enriched in enhancer sequences. Epigenomics $\mathbf{8}$, 389-399, doi:10.2217/epi.15.114 (2016).

54 Barfield, R. T., Kilaru, V., Smith, A. K. \& Conneely, K. N. CpGassoc: an R function for analysis of DNA methylation microarray data. Bioinformatics 28, 1280-1281 (2012).

55 McCartney, D. L. et al. Identification of polymorphic and off-target probe binding sites on the Illumina Infinium MethylationEPIC BeadChip. Genom Data 9, 22-24, doi:10.1016/j.gdata.2016.05.012 (2016).

56 Teschendorff, A. E. et al. A beta-mixture quantile normalization method for correcting probe design bias in Illumina Infinium $450 \mathrm{k}$ DNA methylation data. Bioinformatics 29, 189-196, doi:10.1093/bioinformatics/bts680 (2013).

57 Purcell, S. et al. PLINK: a tool set for whole-genome association and population-based linkage analyses. Am J Hum Genet 81, 559-575, doi:10.1086/519795 (2007).

58 Phipson, B., Maksimovic, J. \& Oshlack, A. missMethyl: an R package for analyzing data from Illumina's HumanMethylation450 platform. Bioinformatics 32, 286-288, doi:10.1093/bioinformatics/btv560 (2016).

59 Chen, J., Bardes, E. E., Aronow, B. J. \& Jegga, A. G. ToppGene Suite for gene list enrichment analysis and candidate gene prioritization. Nucleic acids research 37 , W305W311 (2009).

60 Mo, A. et al. Stratification of Risk of Progression to Colectomy in Ulcerative Colitis using Measured and Predicted Gene Expression. bioRxiv (2021).

61 Liaw, A. \& Wiener, M. Classification and regression by randomForest.

\section{Abbreviations}

Accuracies (ACC)

Area Under the Curve (AUC)

DNA Methylation (DNAm)

Epigenome-Wide Association Studies (EWAS)

False Discovery Rate (FDR) 
Gene Ontology (GO)

Inflammatory Bowel Disease (IBD)

Pediatric Ulcerative Colitis Activity Index (PUCAI)

Predicting Response to Standardized Pediatric Colitis Therapy (PROTECT)

Principle Components (PCs)

Risk Stratification and Identification of Immunogenetic and Microbial Markers of Rapid Disease

Progression in Children with Crohn's Disease (RISK)

Ulcerative Colitis (UC)

\section{Key words}

Children; Epigenetic changes; Inflammatory Bowel Disease; Predicting Response to Standardized

Pediatric Colitis Therapy (PROTECT) study; Risk Stratification and Identification of Immunogenetic and Microbial Markers of Rapid Disease Progression in Children with Crohn's Disease (RISK) study

Data availability. The DNAm data for all the 369 rectal biopsy samples included in this study have been deposited in the Gene Expression Omnibus (GEO) and are accessible through GEO series accession GSE185061. Metadata details regarding subset of patients used in this study are summarized in

\section{Supplementary Table 11.}

\section{Acknowledgements}

We are grateful to Anne Dodd, and Jarod Prince for their support and helpful comments.

\section{Grant support}

This research was supported by the National Institute of Diabetes and Digestive and Kidney Diseases (NIDDK) of the National Institutes of Health (NIH), under grant numbers R21DK119997 (SK) and 
medRxiv preprint doi: https://doi.org/10.1101/2022.01.28.22269598; this version posted January 30, 2022. The copyright holder for this preprint

(which was not certified by peer review) is the author/funder, who has granted medRxiv a license to display the preprint in perpetuity.

It is made available under a CC-BY-NC 4.0 International license .

5U01DK095745 (LAD and JH). This work was also supported by a research initiative grant (RISK) from the Crohn's and Colitis Foundation, New York, NY.

\section{Author Contributions}

K.N.C, A.K.S, H.K.S and S.K. conceived and designed the study. S.V. performed the analysis with input from D.J.C., K.N.C., A.K.S. and G.G. processed samples for methylation profiling. J.S.H., L.A.D. and S.K. participated in the conception and design of the RISK and PROTECT studies. S.V., J.D.M., H.K.S., R. K., G.G., D.J.C., K.N.C., A.K.S., and S.K. interpreted the results and wrote the manuscript. All authors reviewed and approved the manuscript prior to submission.

\section{Competing financial interests}

The authors declare no competing financial interests. 
(a) Controls

(b)
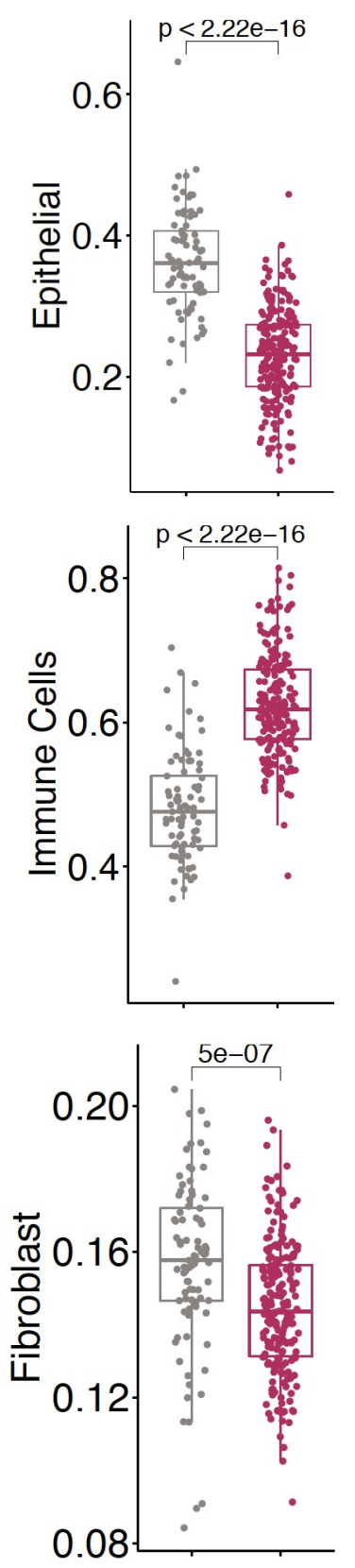

Disease status DNAm 3504 Epithelial CpGs

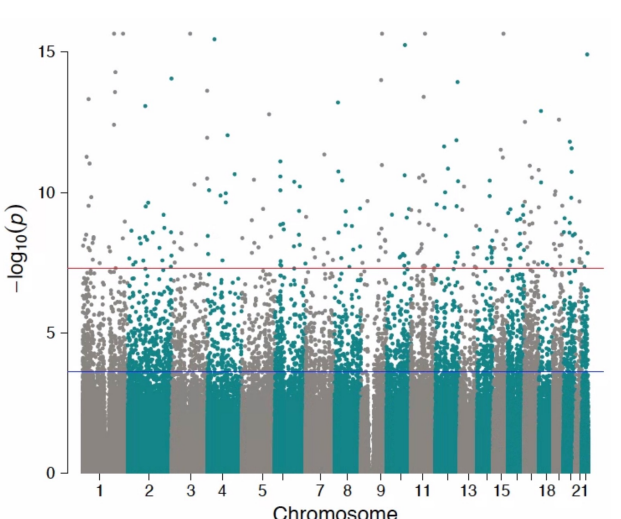

2279 Immune CpGs

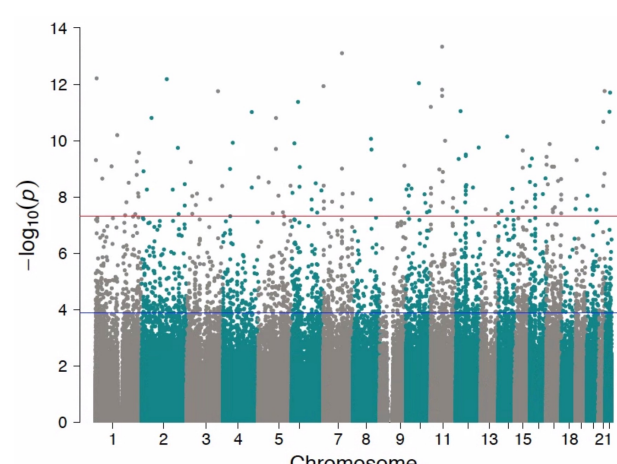

910 Fibroblast CpGs

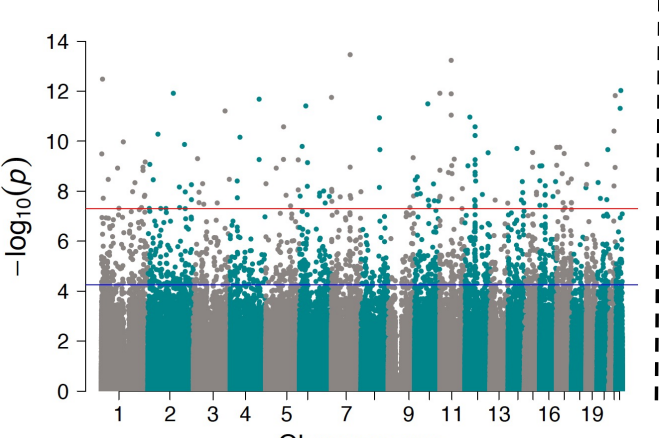

(c)

\section{(d) Pathways}
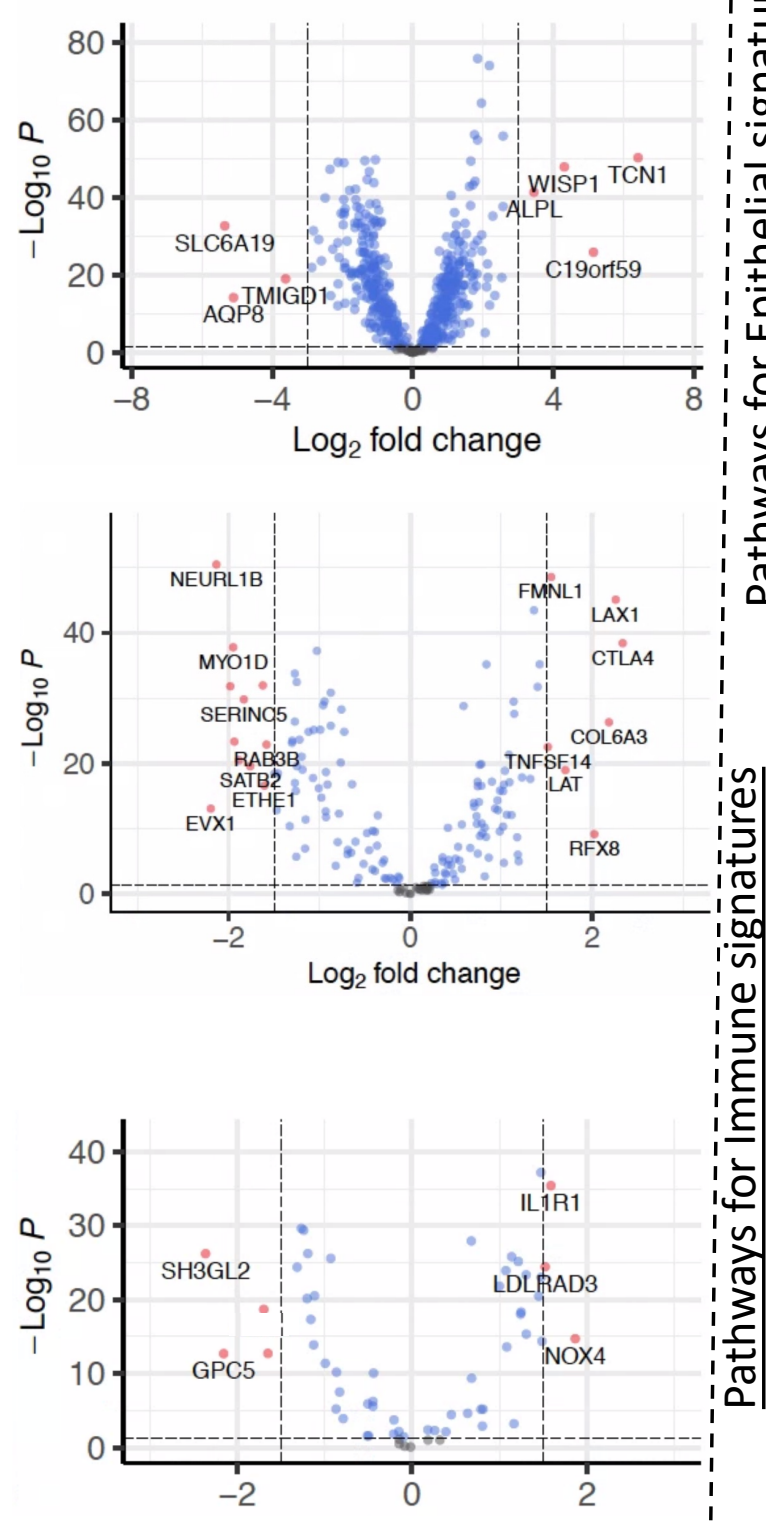
(a) Controls

E' UC at Follow-up
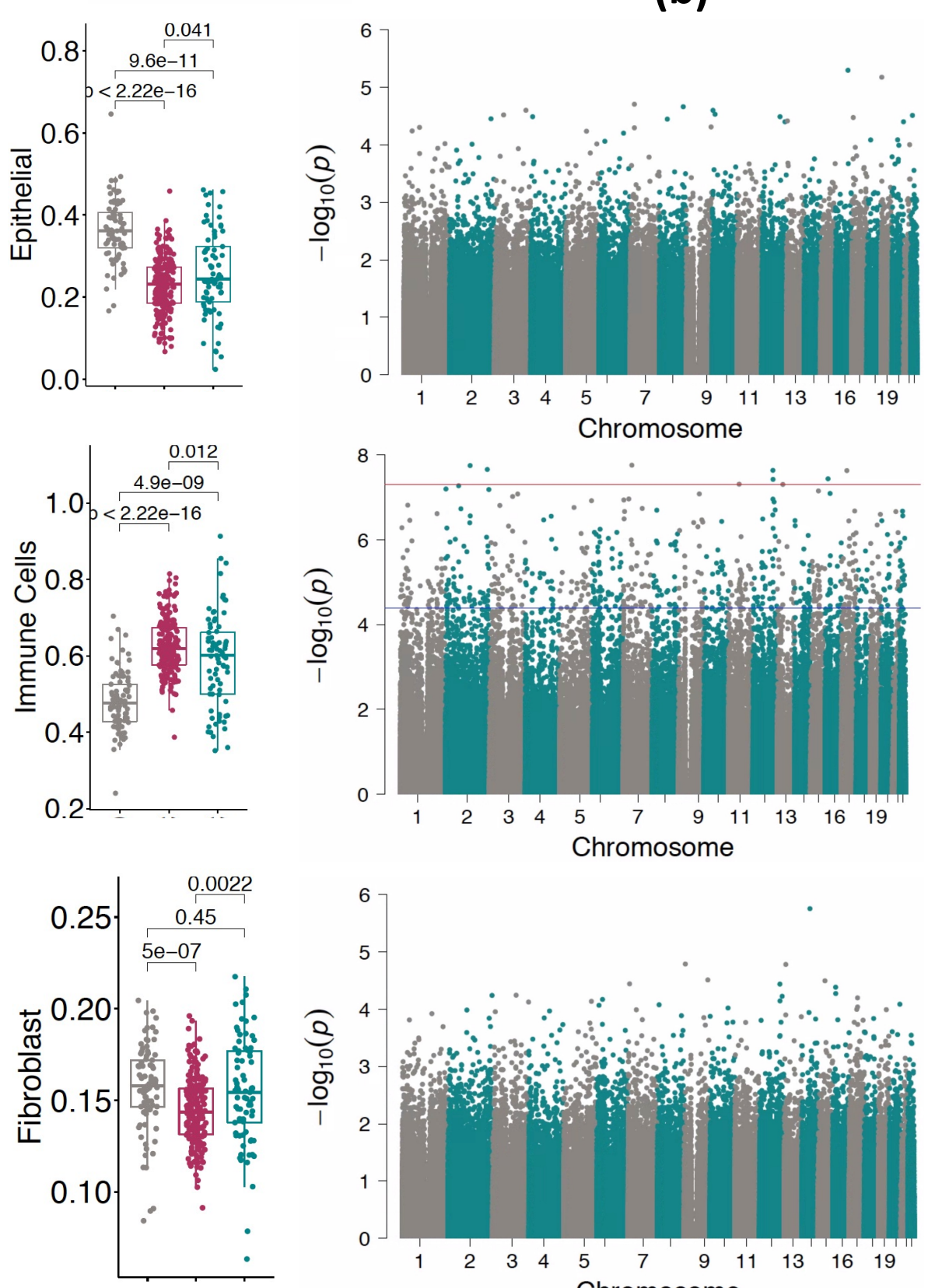

(b)
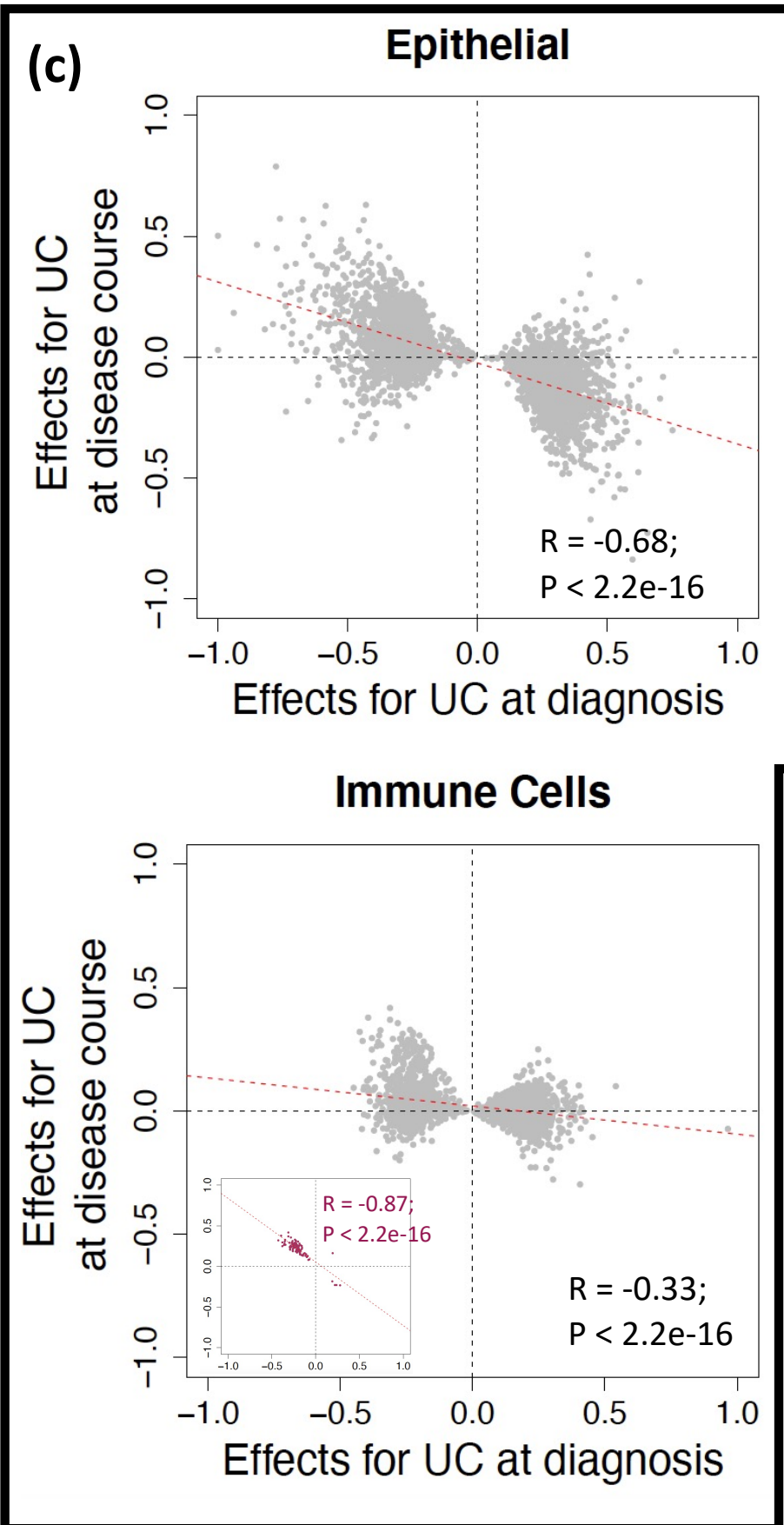

Fibroblasts

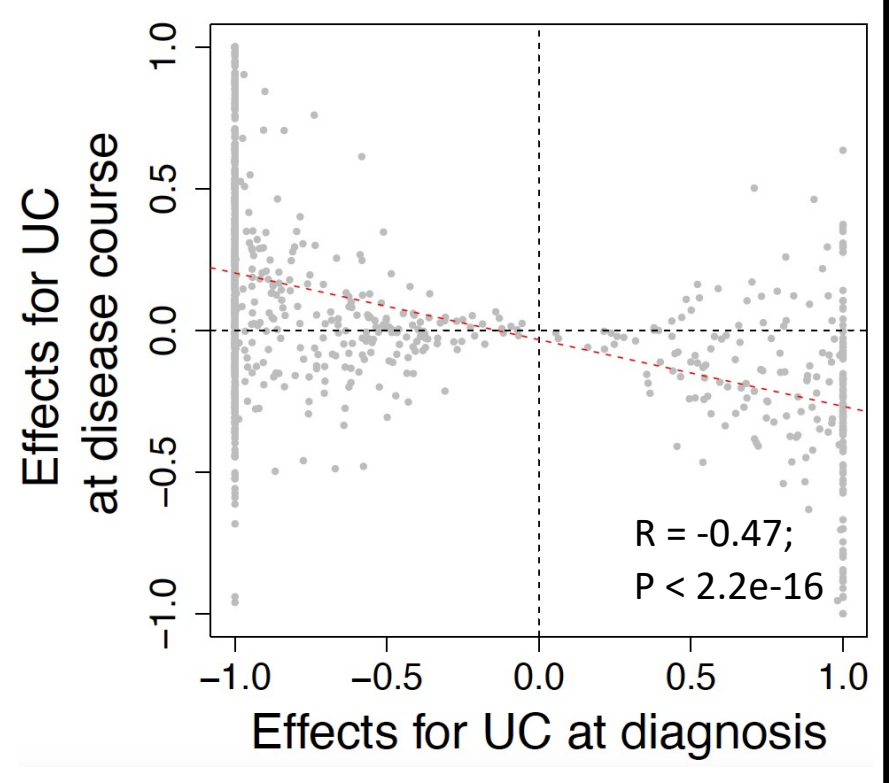

(d)

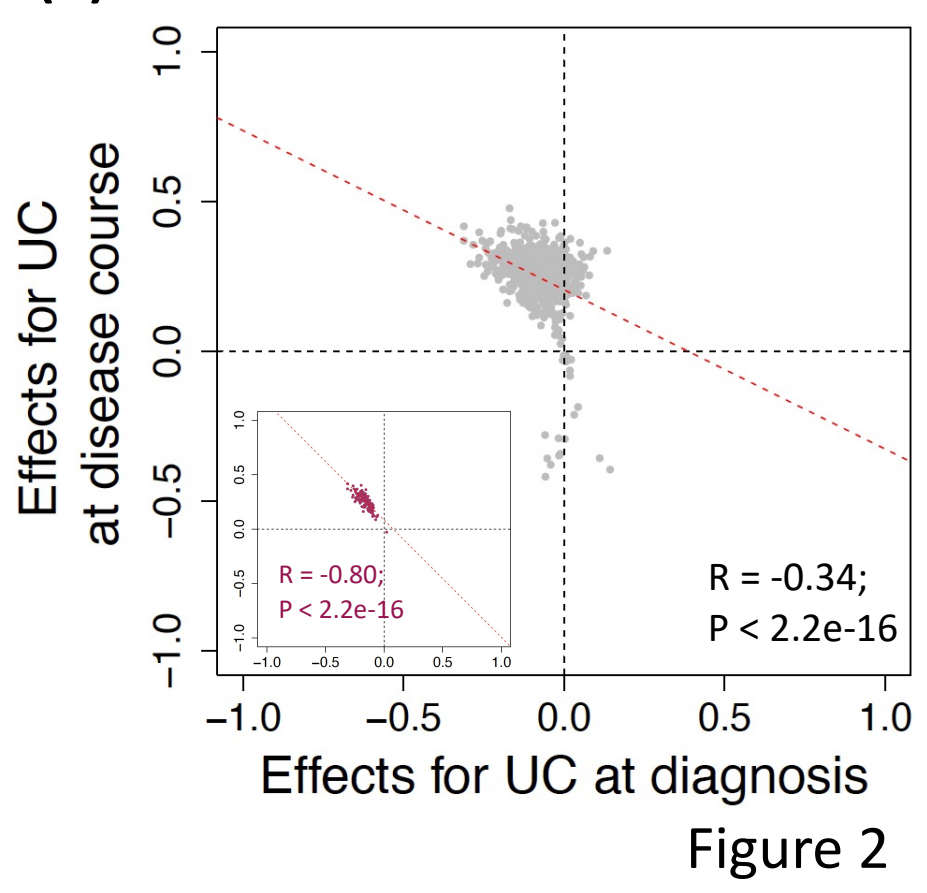


(a)

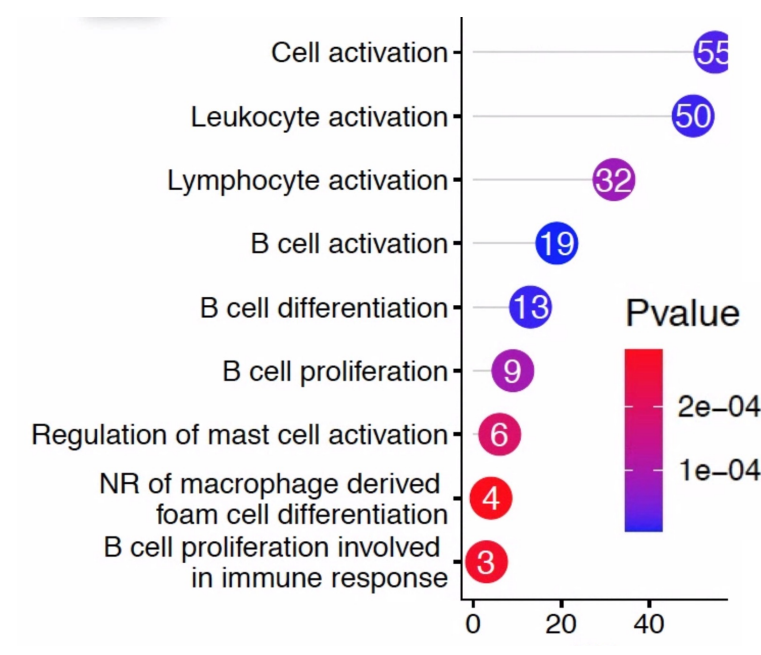

(c)

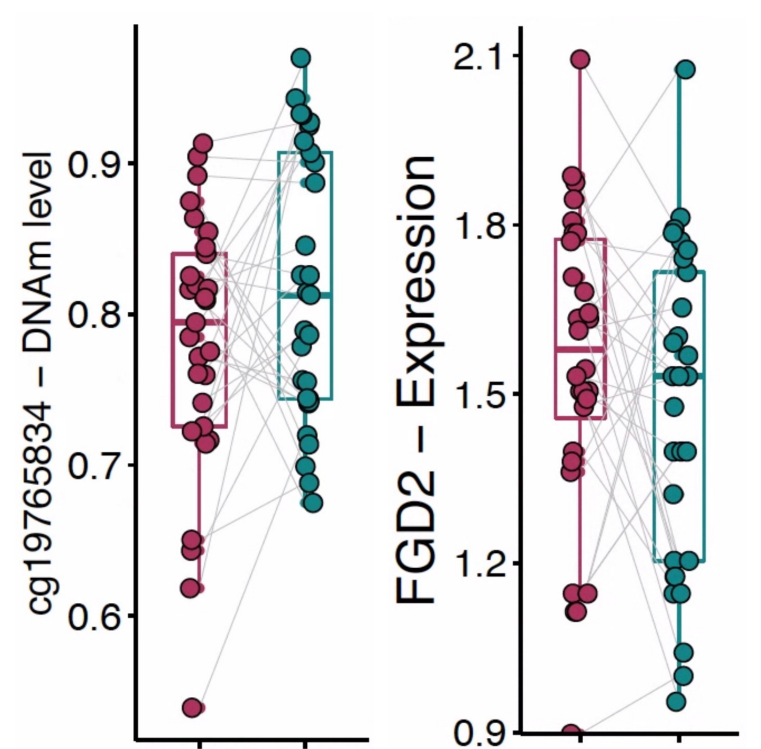

(b)

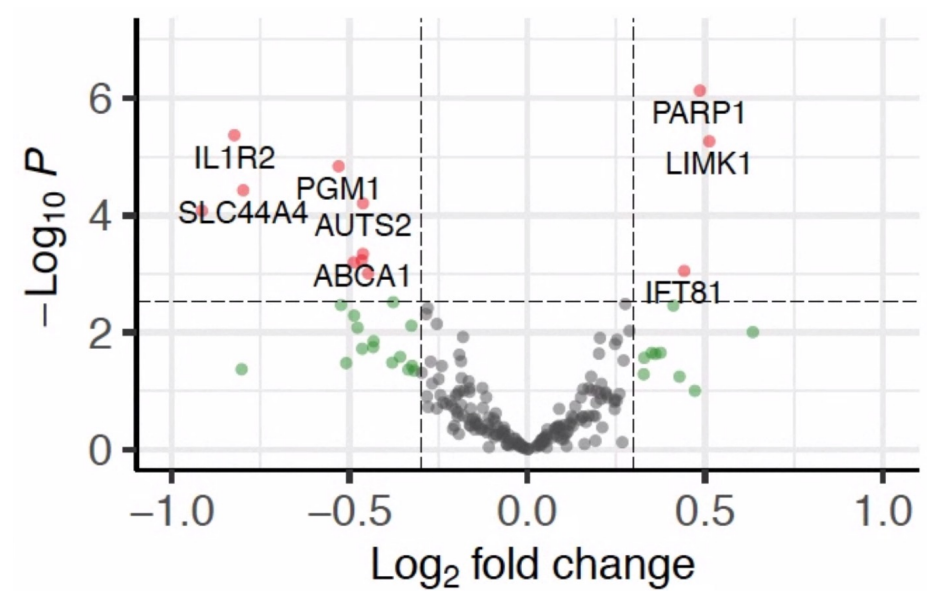

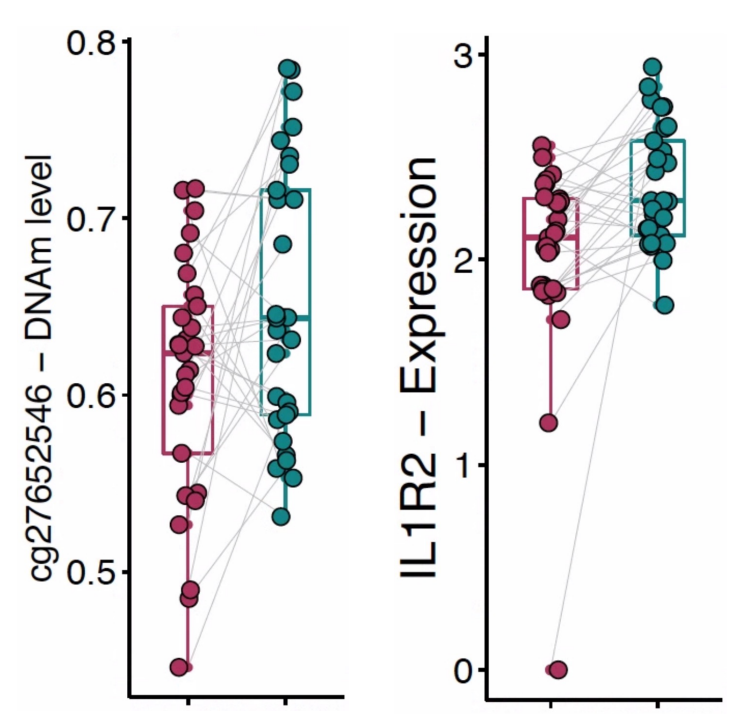

UC at Diagnosis

审 UC at Follow-up 


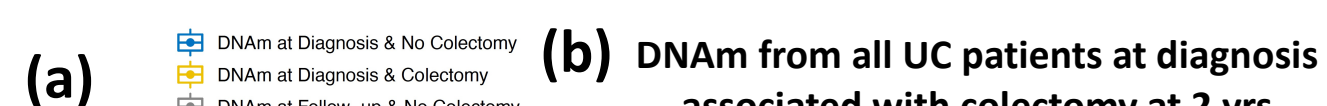

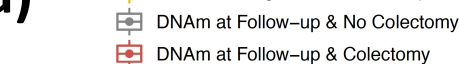

associated with colectomy at 2 yrs

89 Epithelial CpGs
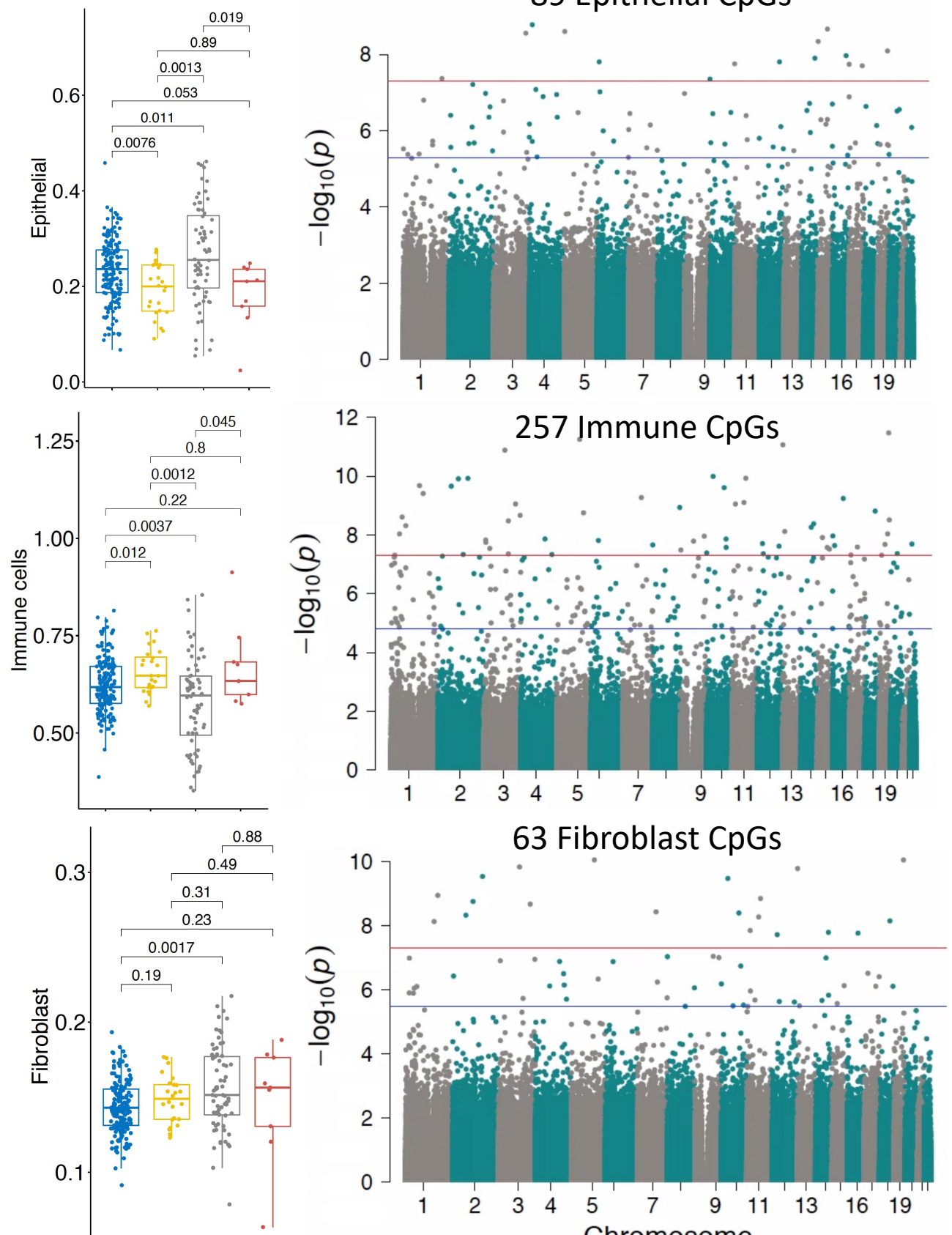

Figure 4 